\title{
Impact of the Quebec Alzheimer Plan on the detection and management of Alzheimer disease and other neurocognitive disorders in primary health care: a retrospective study
}

\author{
Isabelle Vedel PhD, Nadia Sourial MSc, Genevieve Arsenault-Lapierre PhD, \\ Claire Godard-Sebillotte MD, Howard Bergman MD
}

\section{Abstract}

Background: The Quebec Alzheimer Plan aims to improve care provided to patients with neurocognitive disorders in Family Medicine Groups (FMGs) (multidisciplinary team-based primary care practices). The objective of this study was to determine changes in the detection and management of neurocognitive disorders following implementation of the plan, in 2014.

\begin{abstract}
Methods: This was a retrospective chart review before and after implementation of the Quebec Alzheimer Plan in 13 FMGs. We reviewed 1919 randomly selected charts of patients aged 75 years or more and 945 randomly selected charts of patients in this age group with neurocognitive disorders. In the first group, selected outcomes were proportion of patients with documentation of cognitive status, documented diagnosis of neurocognitive disorder, documented cognitive testing and referral to a memory clinic. In patients with neurocognitive disorders, the outcomes were number of contacts with an FMG, quality of follow-up score (documented assessments in 10 domains: cognitive testing, functional status, behavioural and psychological symptoms of dementia, weight, caregiver needs, driving status, home care needs, community service needs, absence of anticholinergic medication and management of dementia medications) and proportion referred to a memory clinic.
\end{abstract}

Results: Significantly more patients aged 75 or more had documentation of cognitive status in their chart after plan implementation than before implementation (440 [45.1\%] v. 351 [37.2\%]) (odds ratio [OR] 1.46, 95\% confidence interval [CI] 1.18-1.81). No significant changes were found in documented diagnosis of neurocognitive disorders, cognitive testing or referral to a memory clinic. Among patients with neurocognitive disorders, the number of contacts with an FMG (adjusted mean difference 1.6, 95\% Cl 0.3-2.8) and quality of follow-up score (adjusted mean difference $6.6,95 \% \mathrm{Cl} 3.9-9.2$ ) increased significantly, without significant changes in the number of referrals to a memory clinic.

Interpretation: The results suggest that the Quebec Alzheimer Plan is feasible and beneficial in terms of detection and management of neurocognitive disorders, without an increase in referral to specialists. The findings will be used to scale up the Quebec Alzheimer Plan and to develop the Canadian federal dementia strategy.

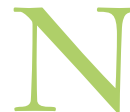
eurocognitive disorders are a major concern worldwide. $^{1}$ Today, an estimated 35.6 million people are affected, and this number is expected to double by 2030. ${ }^{1}$ Nevertheless, the identification, treatment and management of patients with neurocognitive disorders remains suboptimal. Deficiencies in cognitive evaluation and delayed diagnosis result in only half of patients' being identifed. ${ }^{2}$ Inappropriate referral of typical cases to specialists ${ }^{3}$ results in increased wait times for referred patients. ${ }^{4}$ People with neurocognitive disorders also experience inadequate treatment and poor quality of care, including use of potentially inappropriate medication, and poor support for their caregivers, ${ }^{5,6}$ which increases the risk of adverse outcomes. ${ }^{6-9}$ To address these challenges, the World Health Organization has called neurocognitive disorders a public health priority and has encouraged countries to develop dementia action plans. ${ }^{1,10}$ Worldwide, 32 national and subnational plans exist. ${ }^{11}$ In the last 2 decades, several Canadian provinces have developed or are developing plans, and a national dementia strategy has been proposed..$^{12} \mathrm{~A}$ particularity of the Canadian plans is that they are rooted in primary health care, which follows the recommendations of Canadian guidelines on dementia care. ${ }^{13,14}$ The first phase of

Competing interests: None declared.

This article has been peer reviewed.

Correspondence to: Isabelle Vedel, isabelle.vedel@mcgill.ca

CMAJ Open 2019. DOI:10.9778/cmajo.20190053 
the Quebec Alzheimer Plan ${ }^{15}$ was implemented in $2014^{16}$ in 42 Family Medicine Groups (FMGs), which are multidisciplinary team-based primary care practices. ${ }^{17,18}$ A detailed description of the plan is presented in Appendix 1 (available at www.cmajopen.ca/content/7/2/E391/suppl/DC1).

A particularity of the Quebec Alzheimer Plan is that it includes an evaluation strategy. To date, only the French and UK plans included an evaluation plan; neither focuses on primary health care. ${ }^{19-21}$ Moreover, to our knowledge, none of the Canadian plans, which do focus on primary care, have been evaluated. It is thus not clear whether plans based in primary health care improve the care provided to patients with neurocognitive disorders. Our team was mandated by the Quebec Ministry of Health and Social Services to conduct an evaluation to inform a province-wide scale-up. Our study aimed to provide an early-phase evaluation and to determine whether the detection and management of neurocognitive disorders among older patients in primary health care improved after implementation of the Quebec Alzheimer Plan.

\section{Methods}

\section{Design}

We used a retrospective review of independent, randomly selected patient charts before and after implementation of the Quebec Alzheimer Plan to measure the plan's impact. We selected this design over a traditional pre-post evaluation as it mimics more closely a randomized controlled trial. ${ }^{22}$ The chart review was performed in 13 of the 42 FMGs that participated in the first phase of the plan. We selected these 13 FMGs because they were part of public health organizations, which allowed access to charts for research purposes, and they included enough patients to meet sample size requirements (Appendix 2, available at www.cmajopen.ca/content/7/2/E391/ suppl/DC1). Two 9-month periods were considered: a period preceding implementation of the plan (Oct. 1, 2011, to July 1, 2012) and a period following implementation (Oct. 1, 2014, to July 1, 2015). For 6 recently created FMGs, the pre period was Oct. 1, 2012, to July 1, 2013 (Appendix 3, available at www. cmajopen.ca/content/7/2/E391/suppl/DC1). We chose these identical calendar periods to control for seasonal effects and to avoid summer vacation.

This study used a participatory research approach ${ }^{23,24}$ whereby decision-makers, clinicians, patient/caregiver representatives and researchers were involved as coinvestigators during every phase of the study.

\section{Study populations and outcomes}

We obtained chart data for 2 samples: patients aged 75 years or more, and patients aged 75 years or more with neurocognitive disorders. We selected the cut-off of 75 years to ensure a sufficient number of eligible charts of patients with neurocognitive disorders, given the high prevalence of dementia in this population. ${ }^{25}$ For both populations, only patients with a visit to the FMG during the relevant study period were eligible. To ensure independence and avoid overlap, only charts not assessed in the pre period were selected in the post period.
The population of patients aged 75 or more served to obtain data on outcome indicators around the detection of neurocognitive disorders: documentation of cognitive status (note regarding normal cognition, concerns of possible decline by clinician or caregiver, results from cognitive test scores or dementia diagnosis), documented diagnosis of a neurocognitive disorder (dementia, mild cognitive impairment or unspecified neurocognitive disorder), cognitive testing, referral to a memory clinic and justification for referral. Referrals were considered justified if there was an uncertain or differential diagnosis, the presence of depression or behavioural issues, family request or genetic testing. Blank referrals and those including a cognitive status test score without further evaluation were considered unjustified. ${ }^{14,15}$

We collected additional data for patients with neurocognitive disorders to examine indicators of the management and quality of follow-up care. Indicators were the number of contacts with the FMG (in person or by telephone), a quality of follow-up score, use of antipsychotic medication, use of memantine or cholinesterase inhibitors prescribed by the FMG, number of referrals to a memory clinic following diagnosis and justification for referral. Antipsychotic medication included medications belonging to the phenothiazine, butyrophenone, thioxanthene or atypical antipsychotic classification as per the American Hospital Formulary Service PharmacologicTherapeutic Classification through Health Canada Drug Product Database online query. ${ }^{26}$

We based our quality of follow-up indicators on validated tools, ${ }^{27}$ current recommendations and consensus guidelines. ${ }^{14,15,27,28}$ These indicators consisted of documented assessments in 10 domains: cognitive testing, functional status, behavioural and psychological symptoms of dementia, weight, caregiver needs, driving status, home care needs, community service needs (e.g., Alzheimer Society), absence of anticholinergic medication and management of dementia medications. For the identification of anticholinergic medication, we used the Beers criteria, based on the Anatomical Therapeutic Chemical classification system. ${ }^{29}$ The score was based on the validated Assessing Care of Vulnerable Elders-3 approach ${ }^{27}$ and was calculated by summing the number of indicators performed divided by the number of eligible indicators for each patient. We assessed patients' eligibility for each indicator over the study period (e.g., patients who no longer drove would not need a driving evaluation).

We measured site- and patient-level characteristics.

\section{Data collection}

Administrative lists of patients aged 75 years or more were extracted and anonymized. Charts were randomly selected from the lists. We first identified charts of patients aged 75 years or more. For patients in this age group with neurocognitive disorders, we also used an existing vulnerability code in the administrative lists to narrow the search for neurocognitive disorders. Data were collected from the charts and then entered into a secure Web-based database. We tested and refined the database and a detailed 23-page instruction manual through a pilot study. ${ }^{30}$ 
Stringent quality-control measures were put in place during data collection. A senior research nurse trained and monitored a group of 12 research nurses and assistants to conduct the chart review. She performed ongoing quality-control checks for each chart and followed up with the team regarding inconsistencies or data entry errors. The statistician involved in the study also conducted quality-control analyses to uncover irregularities. Problematic entries were reassessed and errors corrected if needed. Because of this close monitoring, there were no missing data for any of the variables studied.

\section{Statistical analysis}

To determine whether the detection and management of neurocognitive disorders changed after the Quebec Alzheimer Plan was implemented, we analyzed the association between study period (before and after implementation) and the study outcomes, adjusting for patient characteristics (age, sex and number of medications). The number of medications is considered a suitable proxy for the level of comorbidity given the incomplete data in the charts on active chronic diseases and the high correlation between the number of medications and number of conditions. ${ }^{31} \mathrm{We}$ fitted a linear and logistic mixed-effects model for continuous and binary outcomes, respectively. As patients within sites were likely more similar than patients across sites, we adjusted the models for the clustered nature of the data by including a site identifier associated with each patient as a random effect in the model. The value of the intraclass correlation coefficient was obtained for each outcome. We used the SAS procedures PROC MIXED and PROC GLIMMIX (SAS 9.3, SAS Institute) to model the associations.

\section{Ethics approval}

The study was approved by the Research Ethics Board of the Centre intégré universitaire de santé et de services sociaux of West-Central Montréal and the ethics committees affiliated with each FMG. Institutional authorization was obtained from each regional health organization where applicable.

\section{Results}

Of the 13 FMGs, 7 (54\%) were university-affiliated, and 6 (46\%) were in urban locations (Appendix 3). The median number of registered patients per site was 16696 (interquartile range 9080-26 408). The median number of full-timeequivalent physicians was 18 (interquartile range 15-20).

Of 3568 potential charts, 1195 (33.5\%) were excluded (Figure 1). Data for 1919 patients aged 75 years or more and 945 patients aged 75 or more with neurocognitive disorders

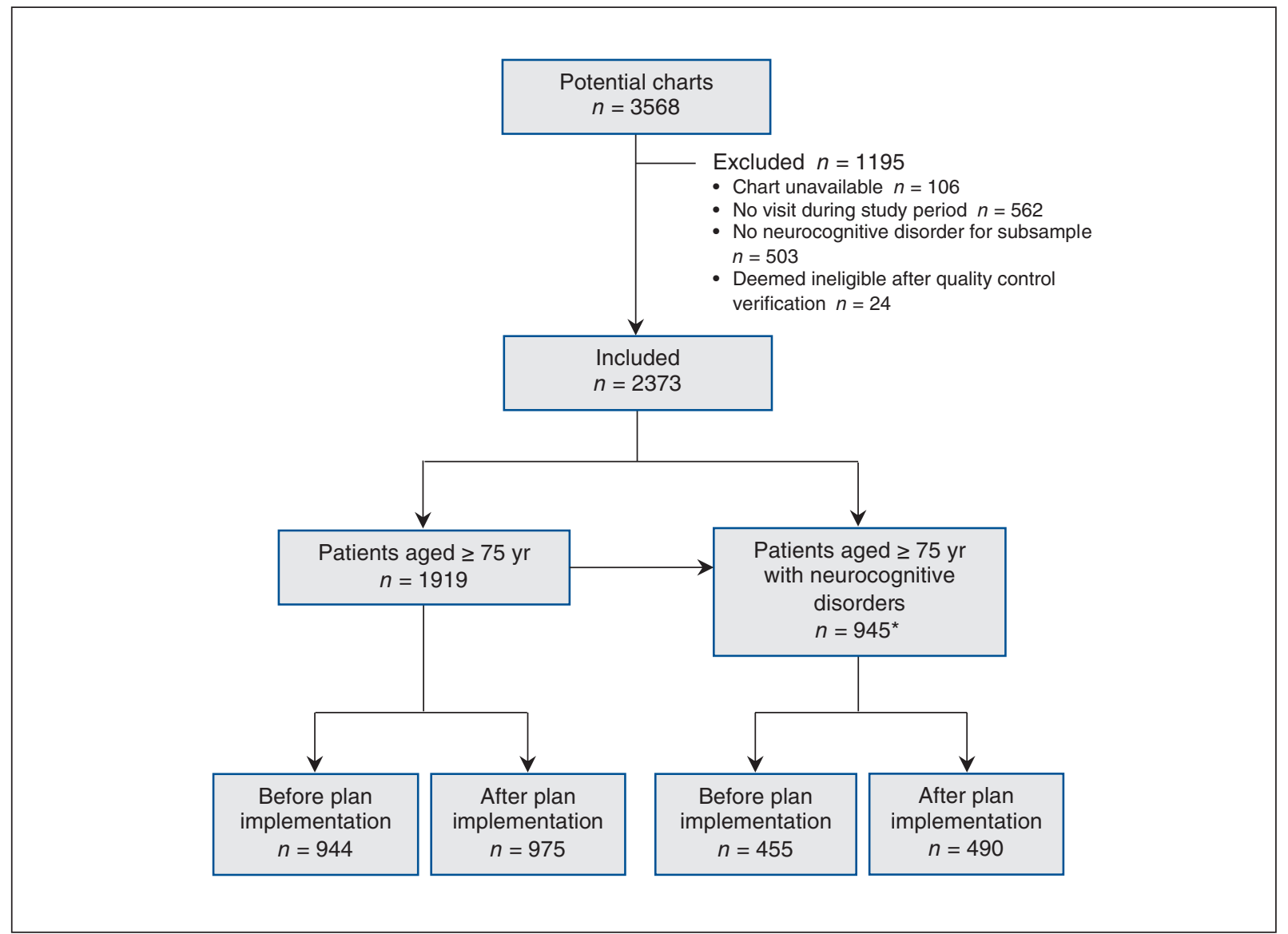

Figure 1: Flow chart showing the screening of eligible charts of patients aged 75 years or more and those aged 75 or more with neurocognitive disorders (dementia, mild cognitive impairment or unspecified neurocognitive disorder) before and after implementation of the Quebec Alzheimer Plan. *Of the 945 patients, 491 were identified while screening for patients eligible for the age 75 or more group. 
were collected. The majority of patients in the former group were women (574 [60.8\%] before plan implementation and 577 [59.2\%] after) (Table 1). The mean patient age was 81.9 years (standard deviation [SD] $5.0 \mathrm{yr}$ ) and 81.7 years (SD $5.0 \mathrm{yr}$ ) in the 2 periods, respectively. Patients aged 75 or more with neurocognitive disorders were also predominantly female (286 [62.9\%] before plan implementation and 300 [61.2\%] after) (Table 2). The corresponding mean patient age was 84.0 (SD 5.3) years and 83.6 (SD 5.1) years. The main types of neurocognitive disorders before and after plan implementation were dementia (304 [66.8\%] and 299 [61.0\%], respectively), unspecified neurocognitive disorders (82 [18.0\%] and 107 [21.8\%], respectively) and mild cognitive impairment (70 [15.4\%] and 84 [17.1\%], respectively) (Table 2).

Significantly more patients aged 75 or more had documentation of cognitive status in their chart after plan implementation than before implementation (440 [45.1\%] v. 351 [37.2\%]) (odds ratio [OR] 1.46, 95\% confidence interval [CI] 1.18-1.81) (Table 3). The corresponding numbers of patients with neurocognitive disorders were $255(26.2 \%)$ and 208 (22.0\%) (OR 1.25, 95\% CI 0.98-1.60); this difference did not reach statistical significance. No change was detected in the proportion of patients aged 75 or more who underwent cognitive testing between the 2 periods (137/940 [14.6\%] before implementation and 166/972 [17.1\%] after implementation) (OR $1.21,95 \%$ CI $0.92-1.60$ ) or were referred to a memory clinic (22/886 [2.5\%] and 19/901 [2.1\%], respectively) (OR 0.84, 95\% CI 0.42-1.68). Most of the referrals before and after implementation were justified (14/22 [64\%] and 16/19 [84\%], respectively).

Among patients with neurocognitive disorders, the mean number of contacts with an FMG increased significantly

\begin{tabular}{|c|c|c|}
\hline \multicolumn{3}{|c|}{$\begin{array}{l}\text { Table 1: Characteristics of patients aged } 75 \text { years or more } \\
\text { before and after implementation of the Quebec Alzheimer } \\
\text { Plan }\end{array}$} \\
\hline \multirow[b]{2}{*}{ Characteristic } & \multicolumn{2}{|c|}{ No. $(\%)$ of patients* } \\
\hline & $\begin{array}{c}\text { Before } \\
n=944\end{array}$ & $\begin{array}{c}\text { After } \\
n=975\end{array}$ \\
\hline Female sex & $574(60.8)$ & $577(59.2)$ \\
\hline Age, yr, mean \pm SD & $81.9 \pm 5.0$ & $81.7 \pm 5.0$ \\
\hline \multicolumn{3}{|l|}{ Age group, yr } \\
\hline $75-79$ & $408(43.2)$ & $439(45.0)$ \\
\hline $80-84$ & $286(30.3)$ & $299(30.7)$ \\
\hline$\geq 85$ & $250(26.5)$ & $237(24.3)$ \\
\hline $\begin{array}{l}\text { No. of medications, mean } \\
\pm \mathrm{SD}\end{array}$ & $11.3 \pm 6.9$ & $11.8 \pm 6.9$ \\
\hline \multicolumn{3}{|l|}{ Living alone } \\
\hline Yes & $179(19.0)$ & $204(20.9)$ \\
\hline No & $458(48.5)$ & $495(50.8)$ \\
\hline Missing & $307(32.5)$ & $276(28.3)$ \\
\hline $\begin{array}{l}\text { Note: } S D=\text { standard deviation. } \\
{ }^{*} \text { Except where noted otherwise. }\end{array}$ & & \\
\hline
\end{tabular}

after plan implementation, from 7.9 (SD 10.2) to 9.9 (SD 9.7) (adjusted mean difference 1.57, 95\% CI 0.30-2.84) (Table 4). A significant increase in the mean quality of follow-up score was observed, from 48.0 (SD 20.0) to 54.6 (SD 18.8) (adjusted mean difference 6.58, 95\% CI 3.929.23). All except 2 (cognitive testing and no anticholinergic medications) of the 10 indicators in the quality follow-up score improved after plan implementation. A significant decrease in the number of patients receiving antipsychotic medication was observed, from 117 (25.7\%) before implementation to $98(20.0 \%)$ after implementation (OR 0.66, $95 \%$ CI $0.47-0.95)$. Last, no change was detected in the proportion of patients referred to a memory clinic following diagnosis (40/338 [11.8\%] before implementation v. 29/340 [8.5\%] after implementation [OR 0.66, 95\% CI 0.37-1.16]). Most postdiagnosis referrals were justified both before and after implementation (31/40 [78\%] and 27/29 [93\%], respectively).

\begin{tabular}{|c|c|c|}
\hline \multirow[b]{2}{*}{ Characteristic } & \multicolumn{2}{|c|}{ No. $(\%)$ of patients* } \\
\hline & $\begin{array}{c}\text { Before } \\
n=455\end{array}$ & $\begin{array}{c}\text { After } \\
n=490\end{array}$ \\
\hline Female sex & $286(62.9)$ & $300(61.2)$ \\
\hline Age, yr, mean \pm SD & $84.0 \pm 5.3$ & $83.6 \pm 5.1$ \\
\hline \multicolumn{3}{|l|}{ Age group, yr } \\
\hline $75-79$ & $118(25.9)$ & $137(28.0)$ \\
\hline $80-84$ & $149(32.8)$ & $174(35.5)$ \\
\hline$\geq 85$ & $188(41.3)$ & $179(36.5)$ \\
\hline $\begin{array}{l}\text { No. of medications, mean } \\
\pm S D\end{array}$ & $12.7 \pm 6.8$ & $13.6 \pm 7.2$ \\
\hline \multicolumn{3}{|l|}{ Type of neurocognitive disorder } \\
\hline Dementia & $304(66.8)$ & $299(61.0)$ \\
\hline Alzheimer disease & $117(38.5)$ & $141(47.2)$ \\
\hline Vascular & $18(5.9)$ & $17(5.7)$ \\
\hline Mixed & $88(29.0)$ & $58(19.4)$ \\
\hline Lewy body & $12(4.0)$ & $5(1.7)$ \\
\hline Frontotemporal & $3(1.0)$ & $1(0.3)$ \\
\hline Other & $4(1.3)$ & $2(0.7)$ \\
\hline Unspecified & $62(20.4)$ & $75(25.1)$ \\
\hline Mild cognitive impairment & $70(15.4)$ & $84(17.1)$ \\
\hline Unspecified & $82(18.0)$ & $107(21.8)$ \\
\hline \multicolumn{3}{|l|}{ Living alone } \\
\hline Yes & $64(14.1)$ & $83(16.9)$ \\
\hline No & $343(75.4)$ & $372(75.9)$ \\
\hline Missing & $48(10.6)$ & $35(7.1)$ \\
\hline
\end{tabular}




\begin{tabular}{|c|c|c|c|c|}
\hline \multirow[b]{2}{*}{ Variable } & \multicolumn{2}{|c|}{ No. $(\%)$ of patients } & \multirow[b]{2}{*}{ OR $(95 \% \mathrm{Cl})$} & \multirow[b]{2}{*}{ ICC } \\
\hline & $\begin{array}{l}\text { Before } \\
n=944\end{array}$ & $\begin{array}{c}\text { After } \\
n=975\end{array}$ & & \\
\hline Documentation of cognitive status & $351(37.2)$ & $440(45.1)$ & $1.46(1.18-1.81)$ & 0.03 \\
\hline $\begin{array}{l}\text { Documented diagnosis of } \\
\text { neurocognitive disorder }\end{array}$ & $208(22.0)$ & $255(26.2)$ & $1.25(0.98-1.60)$ & 0.02 \\
\hline Dementia & $127(13.4)$ & $141(14.5)$ & - & - \\
\hline Mild cognitive impairment & $41(4.3)$ & $52(5.3)$ & - & - \\
\hline Unspecified & $40(4.2)$ & $62(6.4)$ & - & - \\
\hline $\begin{array}{l}\text { No documented diagnosis of } \\
\text { neurocognitive disorder }\end{array}$ & $736(78.0)$ & $720(73.8)$ & - & - \\
\hline Cognitive testing $†$ & $\begin{array}{c}137(14.6) \\
n=940\end{array}$ & $\begin{array}{c}166(17.1) \\
n=972\end{array}$ & $1.21(0.92-1.60)$ & 0.03 \\
\hline Referral to memory clinic $\neq$ & $\begin{array}{l}22(2.5) \\
n=886\end{array}$ & $\begin{array}{l}19(2.1) \\
n=901\end{array}$ & $0.84(0.42-1.68)$ & 0.04 \\
\hline Justified referral§ף ${ }^{\star *}$ & $14(63.6)$ & $16(84.2)$ & - & - \\
\hline Uncertainty & $6(42.9)$ & $7(43.8)$ & - & - \\
\hline Family request & $1(7.1)$ & $5(31.2)$ & & \\
\hline Presence of depression & $1(7.1)$ & $2(12.5)$ & - & - \\
\hline Complex medication management & $3(21.4)$ & $0(0.0)$ & & \\
\hline Complex patient management & $6(42.9)$ & $6(37.5)$ & - & - \\
\hline Other reasonף†† & $2(9.1)$ & $0(0.0)$ & & \\
\hline Unjustified referralף & $6(27.3)$ & $3(15.8)$ & - & - \\
\hline No prior evaluation & $3(50.0)$ & $2(66.7)$ & - & - \\
\hline Blank referral & $3(50.0)$ & $1(33.3)$ & - & - \\
\hline \multicolumn{5}{|c|}{ 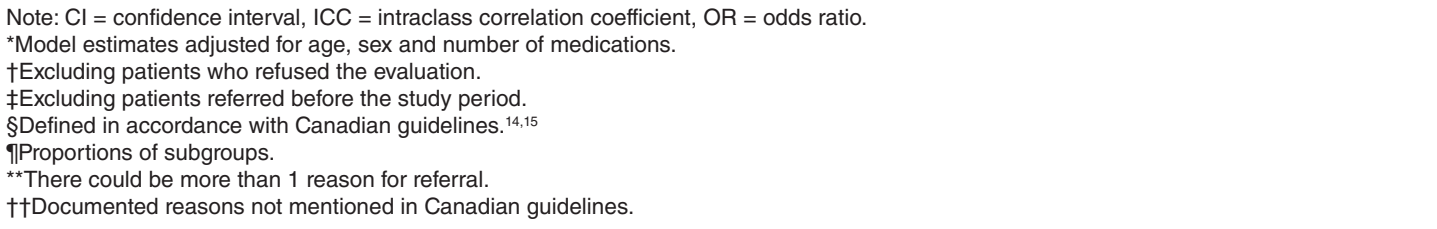 } \\
\hline
\end{tabular}

\section{Interpretation}

Our results showed that, following implementation of the Quebec Alzheimer Plan, the detection of neurocognitive disorders in patients aged 75 years or more improved, as reflected by increased documentation of cognitive status. Moreover, the intensity and quality of management of patients in this age group with neurocognitive disorders also improved, with an increase in the number of contacts with FMGs and the quality of follow-up score and a decrease in antipsychotic medication use.

The increased documentation of cognitive status among patients aged 75 or more suggests that family physicians were more aware of the importance of diagnosing neurocognitive disorders in their patients. This was similar to results in one of the few other plans evaluated, the UK National Dementia Strategy. ${ }^{32}$ However, contrary to the specialist-centred UK strategy, we observed this improvement in documentation of cognitive status without an increase in the number of referrals to memory clinics. This suggests that the primary care focus of the Quebec Alzheimer Plan may have empowered family physicians to diagnose neurocognitive disorders without overly relying on specialists.

In older patients with neurocognitive disorders, we observed an increase in the number of contacts (face-to-face or via telephone or email) with FMGs. This is similar to what was found with a collaborative care model in the United States. ${ }^{33}$ The Quebec Alzheimer Plan also resulted in better management of patients with neurocognitive disorders, as measured by the quality of follow-up score. Similar findings were observed in other intervention studies that looked at compliance with a list of indicators of quality of dementia care. ${ }^{34,35}$ Vickrey and colleagues ${ }^{34}$ compared the charts of patients with dementia who received an intervention aimed at improving their care to those of patients with dementia who received usual care and found better compliance in the 
Table 4: Mixed-effects model results for patients aged 75 years or more with neurocognitive disorders before and after implementation of the Quebec Alzheimer Plan*

\begin{tabular}{|c|c|c|c|c|}
\hline \multirow[b]{2}{*}{ Variable } & \multicolumn{2}{|c|}{ No. (\%) of patients† } & \multirow{2}{*}{$\begin{array}{l}\text { Adjusted mean } \\
\text { difference } \\
(95 \% \mathrm{Cl})\end{array}$} & \multirow[b]{2}{*}{ ICC } \\
\hline & $\begin{array}{l}\text { Before } \\
n=455\end{array}$ & $\begin{array}{c}\text { After } \\
n=490\end{array}$ & & \\
\hline $\begin{array}{l}\text { No. of contacts with Family Medicine } \\
\text { Group, mean } \pm \text { SD }\end{array}$ & $7.9 \pm 10.2$ & $9.9 \pm 9.7$ & $1.57(0.30-2.84)$ & 0.12 \\
\hline Quality of follow-up score, mean \pm SD & $48.0 \pm 20.0$ & $54.6 \pm 18.8$ & $6.58(3.92-9.23)$ & 0.08 \\
\hline Cognitive testing $\ddagger$ & $\begin{array}{c}226(50.1) \\
n=451\end{array}$ & $\begin{array}{l}239(49.2) \\
n=486\end{array}$ & - & - \\
\hline Evaluation of functional status & $317(69.7)$ & $397(81.0)$ & - & - \\
\hline $\begin{array}{l}\text { Evaluation of behavioural and } \\
\text { psychological symptoms of dementia }\end{array}$ & $318(69.9)$ & $398(81.2)$ & - & - \\
\hline Evaluation of weight $\ddagger \S$ & $\begin{array}{c}265(59.3) \\
n=447\end{array}$ & $\begin{array}{c}346(70.9) \\
n=488\end{array}$ & - & - \\
\hline Evaluation of caregiver needs & $\begin{array}{l}107(24.0) \\
n=445\end{array}$ & $\begin{array}{c}133(28.0) \\
n=475\end{array}$ & - & - \\
\hline Documentation of driving status & $\begin{array}{c}52(13.1) \\
n=398\end{array}$ & $\begin{array}{c}98(23.7) \\
n=414\end{array}$ & - & - \\
\hline No anticholinergic medication & $385(84.6)$ & $396(80.8)$ & - & - \\
\hline $\begin{array}{l}\text { Evaluation of home-based service } \\
\text { needs }\end{array}$ & $237(52.1)$ & $294(60.0)$ & - & - \\
\hline Evaluation of community service needs & $8(1.8)$ & $33(6.7)$ & - & - \\
\hline \multirow[t]{2}{*}{$\begin{array}{l}\text { Management of dementia medications } \\
\text { (memantine and cholinesterase } \\
\text { inhibitors) })^{\star \star}\end{array}$} & $\begin{array}{c}94(54.3) \\
n=173\end{array}$ & $\begin{array}{c}105(66.9) \\
n=157\end{array}$ & - & - \\
\hline & & & OR $(95 \% \mathrm{Cl})$ & \\
\hline Antipsychotic medication & $117(25.7)$ & $98(20.0)$ & $0.66(0.47-0.95)$ & 0.04 \\
\hline $\begin{array}{l}\text { Memantine or cholinesterase } \\
\text { inhibitors prescribed by Family } \\
\text { Medicine Groupt† }\end{array}$ & $\begin{array}{c}27(71.0) \\
n=38\end{array}$ & $\begin{array}{l}26(72.2) \\
n=36\end{array}$ & $0.81(0.23-2.81)$ & 0.01 \\
\hline $\begin{array}{l}\text { Referral to memory clinic after } \\
\text { diagnosisł‡ }\end{array}$ & $\begin{array}{l}40(11.8) \\
n=338\end{array}$ & $\begin{array}{l}29(8.5) \\
n=340\end{array}$ & $0.66(0.37-1.16)$ & 0.001 \\
\hline Justified referral§§ণી & $31(77.5)$ & $27(93.1)$ & - & - \\
\hline Uncertainty & $14(45.2)$ & $16(59.3)$ & - & - \\
\hline Family request & $4(12.9)$ & $6(22.2)$ & - & - \\
\hline Presence of depression & $2(6.4)$ & $3(11.1)$ & - & - \\
\hline Complex medication management & $4(12.9)$ & $0(0.0)$ & - & - \\
\hline Complex patient management & $11(35.5)$ & $10(37.0)$ & - & - \\
\hline Other reason§§ & $1(2.5)$ & $0(0.0)$ & - & - \\
\hline Unjustified referral§§ & $8(20.0)$ & $2(6.9)$ & - & - \\
\hline No prior evaluation & $4(50.0)$ & $1(50.0)$ & - & - \\
\hline No justification & $4(50.0)$ & $1(50.0)$ & - & - \\
\hline \multicolumn{5}{|c|}{ 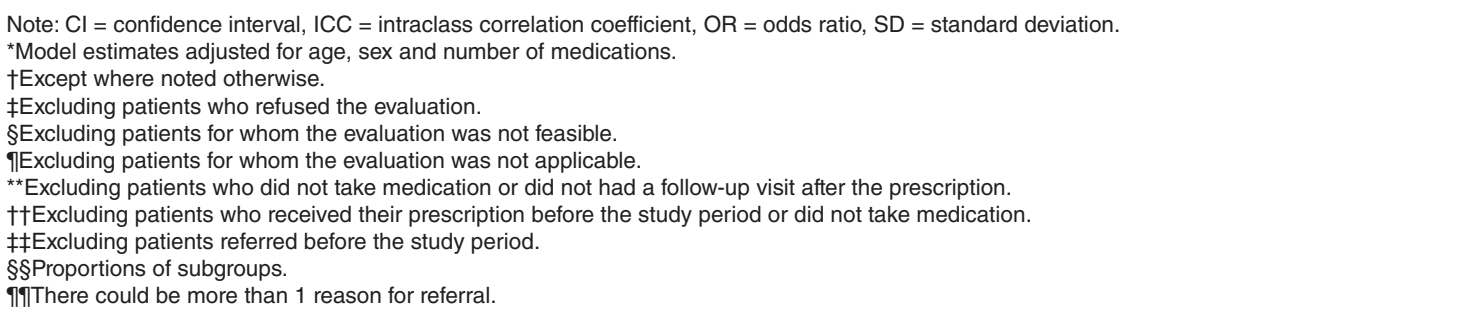 } \\
\hline
\end{tabular}


intervention group (64\% v. $33 \%)$. Reuben and colleagues 35 compared the charts of patients with dementia before and after a quality-of-care intervention and found higher compliance with quality indicators after the intervention $(38 \% \mathrm{v}$. $46 \%$ ). Direct comparison of quality scores is, however, difficult given differences in the indicators used. However, similar to these 2 studies, our study showed that clinicians performed more functional status assessments and evaluation of behavioural and psychological symptoms of dementia following implementation of the Quebec Alzheimer Plan. Like Vickrey and colleagues, ${ }^{34}$ we found an improvement in the evaluation of driving status; however, the proportion of patients in whom driving was evaluated was lower than in their study. We found an improvement in documentation of management of dementia medications, whereas Reuben and colleagues ${ }^{35}$ showed a decrease in the rate of documented discussion of cholinesterase inhibitors. There was a decrease in the number of patients receiving antipsychotics after implementation of the Quebec Alzheimer Plan. This may have been due to training of family physicians, but after plan implementation these rates still remained in the range of what has been found in Canada without an intervention, ${ }^{36}$ and the improvement was lower than that reported by Reuben and colleagues. ${ }^{35}$ An intervention specifically focused on deprescribing antipsychotics could be added to the Quebec Alzheimer Plan. ${ }^{37}$ Some indicators of the quality of follow-up - evaluation of caregiver needs, of driving status and of community service needs - were performed in less than $50 \%$ of patients with neurocognitive disorders, even after plan implementation. Evaluation of caregiver needs and of driving ability is difficult, and clinicians may not feel adequately equipped to perform these evaluations. ${ }^{5}$ Clinicians are also not usually fully aware of existing community services. ${ }^{5,38}$ For these indicators, several targeted interventions at the clinical or organizational levels could be added to the plan.

\section{Limitations}

Although we could not conduct a randomized controlled trial, using randomly selected independent charts in both study periods allowed us to more closely mimic a randomized controlled trial than other quasi-experimental designs. ${ }^{22}$ The random selection of charts in the 2 periods ensured representative samples of the target population. We used a pre-post design, the best possible design given that implementation of the Quebec Alzheimer Plan was a natural experiment. In addition, the chart review allowed us to capture not only inperson physician visits but also contacts with nurses, a key aspect of FMGs, as well as telephone calls. The monitoring of data collection yielded high-quality data (no missing data). Although we could not account for potential temporal trends, our qualitative assessments (results not shown) provided support that no other interventions were ongoing during the study period that could have contributed to the observed changes. Chart reviews measure only what is documented in patients' files. However, it has been shown that increased quality of documentation is predictive of increased quality of care ${ }^{39}$ Finally, we chose a post period early after plan implementation because of the need for rapid knowledge transfer to the Quebec Ministry of Health and Social Services before province-wide scale-up. The observed differences are thus a conservative estimation.

\section{Conclusion}

Our study contributes important knowledge on the earlyphase evaluation of a dementia action plan centred in primary health care. The findings will be used to scale up the Quebec Alzheimer Plan and to develop the Canadian federal dementia strategy. Our results suggest that it is feasible and beneficial to anchor dementia plans in primary health care and that a plan centred in primary care can improve the capacity of family physicians in FMGs to provide dementia care. It seems essential that policy-makers, health care managers and clinicians be more confident in the capacity of family physicians to care for patients with neurocognitive disorders.

\section{References}

1. Dementia: a public bealth priority. Geneva: World Health Organization; 2012. Available: https://extranet.who.int/agefriendlyworld/wp-content/uploads/ 2014/06/WHO-Dementia-English.pdf (accessed 2014 Dec. 1).

2. Early detection and diagnosis of Alzheimer's dementia [policy brief]. Chicago: Alzheimer's Association; 2017. Available: http://act.alz.org/site/DocServer/ Policy_Brief_-_Early_Detection_and_Diagnosis_Brief_Assn.pdf?docID=53576 (accessed 2017 Sept. 1).

3. Kada S, Nygaard HA, Geitung JT, et al. Quality and appropriateness of referrals for dementia patients. Qual Prim Care 2007;15:53-7.

4. Hodge S, Hailey E. Second English national memory clinics audit report. London (UK): Royal College of Psychiatrists; 2015.

5. Aminzadeh F, Molnar FJ, Dalziel WB, et al. A review of barriers and enablers to diagnosis and management of persons with dementia in primary care. Can Geriatr 7 2012;15:85-94.

6. Rising tide: the impact of dementia on Canadian society. Toronto: Alzheimer Society of Canada; 2010.

7. Sternberg SA, Wolfson C, Baumgarten M. Undetected dementia in communitydwelling older people: the Canadian Study of Health and Aging. 7 Am Geriatr Soc 2000; $48: 1430-4$.

8. Steele C, Rovner B, Chase GA, et al. Psychiatric symptoms and nursing home placement of patients with Alzheimer's disease. Am F Psychiatry 1990;147:1049-51.

9. Amjad H, Carmichael D, Austin AM, et al. Continuity of care and health care utilization in older adults with dementia in fee-for-service Medicare. $7 A M A$ Intern Med 2016;176:1371-8.

10. The epidemiology and impact of dementia: current state and future trends. Geneva: World Health Organization; 2015. Available: www.who.int/mental_health/ neurology/dementia/dementia_thematicbrief_epidemiology.pdf?ua=1 (accessed 2018 Apr. 1).

11. From plan to impact: progress towards targets of the Global action plan on dementia. London (UK): Alzheimer's Disease International; 2018. Available: www.alz. co.uk/adi/pdf/from-plan-to-impact-2018.pdf (accessed 2018 Dec. 1).

12. Latest assessments in progress. Ottawa: Canadian Academy of Health Sciences; 2018. Available: www.cahs-acss.ca/latest-assessments-in-progress/? (accessed 2018 July 11).

13. Gauthier S, Patterson C, Chertkow H, et al. Recommendations of the 4th Canadian Consensus Conference on the Diagnosis and Treatment of Dementia. Can Geriatr 7 2012;15:120-6.

14. Proceedings of the Third Canadian Consensus Conference on Diagnosis and Treatment of Dementia. 146 approved recommendations: final - July 2007. 2016 Mar. 9-11; Montréal. Available: www.cccdtd.ca/pdfs/Final_Recommendations_ CCCDTD_2007.pdf (accessed 2018 Apr. 1).

15. Ministère de la Santé et des Services Sociaux du Québec. Relever le défi de la maladie d'Alzheimer et des maladies apparentées : une vision centrée sur la personne, l'bumanisme et l'excellence. Rapport du comité d'experts en vue de l'élaboration d'un plan d'action pour la maladie d'Alzheimer [report]. Québec: Gouvernement du Québec; 2009. Available: http://publications.msss.gouv.qc.ca/msss/ document-000869/ (accessed 2015 Jan. 1).

16. Ministère de la Santé et des Services sociaux. Cadre général de projet: projets d'implantation ciblée en GMF pour rehausser l'accès aux services de santé et services sociaux avec le soutien des $2^{e}$ et $3^{e}$ lignes de services. Québec: Gouvernement du Québec; 2014. Available: http://publications.msss.gouv.qc.ca/msss/fichiers/ 2014/14-829-01W.pdf (accessed 2015 Jan. 1). 
17. Diop M, Fiset-Laniel J, Provost S, et al. Does enrollment in multidisciplinary team-based primary care practice improve adherence to guidelinerecommended processes of care? Quebec's Family Medicine Groups, 20022010. Health Policy 2017;121:378-88.

18. Strumpf E, Ammi M, Diop M, et al. The impact of team-based primary care on health care services utilization and costs: Quebec's Family Medicine Groups. 7 Health Econ 2017;55:76-94.

19. Wortmann M. Importance of national plans for Alzheimer's disease and dementia. Alzheimers Res Ther 2013;5:40.

20. Ankri J, Van Broeckhoven C. Évaluation du plan Alzheimer 2008-2012 [report]. Paris: Ministère des Solidarités et de la Santé; 2013.

21. Improving the dementia diagnosis rate in North East England 2013: an update on prevalence rates; diagnosis rates; crisis related hospital admissions. London (UK): Public Health England; 2013.

22. Hernán MA, Robins JM. Causal inference. Boca Raton (FL): Chapman \& Hall/ CRC; 2019 (forthcoming). Available: www.hsph.harvard.edu/miguel-hernan/ causal-inference-book/ (accessed 2019 Apr. 30).

23. Bush PL, Pluye P, Loignon C, et al. Organizational participatory research: a systematic mixed studies review exposing its extra benefits and the key factors associated with them. Implement Sci 2017;12:119.

24. Jagosh J, Macaulay AC, Pluye P, et al. Uncovering the benefits of participatory research: implications of a realist review for health research and practice. Milbank Q 2012;90:311-46.

25. Canadian Study of Health and Aging: study methods and prevalence of dementia. CMA7 1994;150:899-913.

26. Drug Product Database online query. Ottawa: Health Canada; modified 2018 Dec. 14. Available: https://health-products.canada.ca/dpd-bdpp/index-eng.jpp (accessed 2019 Jan. 31).

27. Wenger NS, Roth CP, Shekelle P; ACOVE Investigators. Introduction to the Assessing Care of Vulnerable Elders-3 quality indicator measurement set. $7 \mathrm{Am}$ Geriatr Soc 2007;55(Suppl 2):S247-52.

28. Callahan CM, Sachs GA, LaMantia MA, et al. Redesigning systems of care for older adults with Alzheimer's disease. Health Aff (Millwood) 2014; 33:626-32.

29. American Geriatrics Society 2015 Beers Criteria Update Expert Panel. American Geriatrics Society 2015 updated Beers Criteria for potentially inappropriate medication use in older adults. 7 Am Geriatr Soc 2015;63:2227-46.

30. Vedel I, Le Berre M, Sourial N, et al. Shedding light on conditions for the successful passive dissemination of recommendations in primary care: a mixed methods study. Implement Sci 2018;13:129.

31. Schneeweiss S, Seeger JD, Maclure M, et al. Performance of comorbidity scores to control for confounding in epidemiologic studies using claims data. Am 7 Epidemiol 2001;154:854-64.

32. Iliffe $S$, Wilcock J. The UK experience of promoting dementia recognition and management in primary care. Z Gerontol Geriatr 2017;50(Suppl 2):63-7.

33. Callahan CM, Boustani MA, Unverzagt FW, et al. Effectiveness of collaborative care for older adults with Alzheimer disease in primary care: a randomized controlled trial. FAMA 2006;295:2148-57.

34. Vickrey BG, Mittman BS, Connor KI, et al. The effect of a disease management intervention on quality and outcomes of dementia care: a randomized, controlled trial. Ann Intern Med 2006;145:713-26.
35. Reuben DB, Roth CP, Frank JC, et al. Assessing care of vulnerable elders Alzheimer's disease: a pilot study of a practice redesign intervention to improve the quality of dementia care. 7 Am Geriatr Soc 2010;58:324-9.

36. Kirkham J, Sherman C, Velkers C, et al. Antipsychotic use in dementia: Is there a problem and are there solutions? Can 7 Psychiatry 2017;62:170-81.

37. Reeve E, Gnjidic D, Long J, et al. A systematic review of the emerging definition of 'deprescribing' with network analysis: implications for future research and clinical practice. Br 7 Clin Pharmacol 2015;80:1254-68.

38. Dodd E, Cheston R, Fear T, et al. An evaluation of primary care led dementia diagnostic services in Bristol. BMC Health Serv Res 2014;14:592.

39. Zegers M, de Bruijne MC, Spreeuwenberg P, et al. Quality of patient record keeping: An indicator of the quality of care? BMF Qual Saf 2011;20:314-8.

Affiliations: Department of Family Medicine (Vedel, Sourial, GodardSebillotte, Bergman), McGill University; Lady Davis Institute (Vedel, Sourial, Arsenault-Lapierre), Jewish General Hospital, Montréal, Que.

Contributors: Isabelle Vedel, Nadia Sourial and Genevieve ArsenaultLapierre contributed to drafting the manuscript, and Claire GodardSebillotte and Howard Bergman critically appraised it for important intellectual content. All of the authors contributed to the study conception and design, and interpretation of results, approved the version to be published and agreed to be accountable for all aspects of the work.

Funding: This work was supported by the Fonds de recherche du Québec - Santé and grant CNA-137794 from the Canadian Consortium on Neurodegeneration in Aging, Canadian Institutes of Health Research.

Acknowledgements: This work would not have been possible without the contribution of many members of the research team. The authors acknowledge the work of Marine Hardouin, Mary Henein, Zoë Tremblay, Lucie Vaillancourt, Mélanie Le Berre, Rachel Simmons, Maxime Guillette, Yves Couturier, Matthew Hacker Teper, Muriel Gueriton, Martin Beauchamp, Geva Maimon, Dominique Tremblay, Sarah Ousalem, Lise Messier, and Chantal Boislard. Anne-Marie Simard, Christine Fournier, Christian Boutin and Eric Maubert from the Quebec Ministry of Health and Social Services also helped with the selection of outcomes and provided useful contact information. The authors extend their appreciation to patients and caregivers' representatives and the many local project managers, family physicians, nurses, administrative coordinators, archivists and medical directors from the Family Medicine Groups participating in the Quebec Alzheimer Plan for their help with data collection.

Disclaimer: The funders had no role in the study design, data collection or interpretation, or conclusions.

Supplemental information: For reviewer comments and the original submission of this manuscript, please see www.cmajopen.ca/content $/ 7 / 2$ / E391/suppl/DC1. 